\title{
Road-kill of Mammals in Nova Scotia
}

\author{
David Fudge ${ }^{1,2}$, Bill Freedman ${ }^{1}$, Michael Crowell $^{2}$, Tony Nette ${ }^{3}$, and Vince Power ${ }^{3}$ \\ ${ }^{1}$ Department of Biology, Dalhousie University, Halifax, Nova Scotia B3H 4J1 Canada \\ 2 Jacques-Whitford Environment Limited, 3 Spectacle Lake Road, Dartmouth, Nova Scotia B3B 1Q9 Canada \\ ${ }^{3}$ Nova Scotia Department of Natural Resources, Wildlife Branch, Kentville, Nova Scotia B4N 4E5 Canada
}

Fudge, David, Bill Freedman, Michael Crowell, Tony Nette, and Vince Power. 2007. Road-kill of mammals in Nova Scotia. Canadian Field-Naturalist 121(3): 265-273.

We examined road mortality of wild mammals in Nova Scotia using data from (a) five years of province-wide data on wildlife collisions involving larger mammals, and (b) 20 months of observations of smaller mammals along a 160-km route near Halifax. An average of 2079 White-tailed Deer was reported killed annually on highways during 1999 through 2003 , along with 14 Moose and 33 Black Bear. Female White-tailed Deer were more likely to be road-killed than males (by a factor of 1.8), yearlings more so than older animals, and there were peaks of mortality in the late spring and late autumn. The road-kill of smaller mammals was highest in the summer and least in the winter, and the most frequent mortalities were of Raccoon (28\% of observations), Porcupine (27\%), Skunk (17\%), Snowshoe Hare (6\%), Coyote (4\%), and Groundhog (3\%). The standardized kill-rate (number/100 km) was highest on a 100-series highway compared to trunk highways or urban streets, but the rate standardized to vehicle density was highest on trunk highways.

Key Words: White-tailed Deer, Odocoileus virginianus, Moose, Alces alces, Black Bear, Ursus americanus, Raccoon, Procyon lotor, Porcupine, Erethizon dorsatum, Skunk, Mephitus mephitis, Snowshoe Hare, Lepus americanus, Coyote, Canis latrans, Groundhog, Marmota monax, road-kill, mortality, wild mammals, Nova Scotia.

Roads are a defining feature of modern transportation systems. Networks of public roads connect population centers, allowing the movement of people and goods in increasingly larger numbers of fast-moving vehicles. Because much highway infrastructure traverses wildlife habitat, an unfortunate consequence is accidental collisions that threaten the lives of both people and animals, while also causing damage to property (Romin and Bissonette 1996). In Nova Scotia, for example, 503 collisions between vehicles and large wild mammals were reported in 2003, with 68 of the incidents resulting in personal injury requiring emergency services (NSDTPW 2006*). Data relating to the economic costs of such accidents have been quantified in Maine, where they result in US\$32 million/year in property damage and medical costs (MEDOT 2001*). Overall in the United States, vehicle accidents involving only White-tailed Deer (Odocoileus virginianus) annually result in about 200 human fatalities, 30 thousand injuries, and more than US $\$ 1$ billion in property damage (Conover 1997). In Europe, collisions with ungulates result in 300 human fatalities and US $\$ 1$ billion in property damage annually (Bruinderink and Hazebroek 1996). Clearly, a large socio-economic cost is associated with collisions with large animals on roads.

Roads also have important ecological impacts, including the following: (a) damage to populations of some species through mortality; (b) acting as barriers to movement or disrupting behaviour in other ways; (c) destroying and fragmenting natural habitat; (d) causing pollution by de-icing salt, metals, and pesticides; and (e) enhancing access for hunters (Bennet 1991; Evink 1999). The direct mortality of larger animals due to vehicle collisions is relatively apparent and wellquantified (Clarke et al. 1998; Cain et al. 2003; Clevenger et al. 2003; Saeki and MacDonald 2004). Roadkill may affect the conservation status of species about $65 \%$ of the mortality of the endangered Florida Panther (Puma concolor coryi) is caused by vehicular collisions (Harris and Gallagher 1989). Other at-risk populations threatened by road-kill mortality include Ocelot (Leopardus pardalis) in the U.S. southwest (Tewes and Blanton 1998), the European Badger (Meles meles) in Great Britain (Clarke et al. 1998), and the endangered mainland Moose of Nova Scotia (Alces alces americana) (NSDNR 2008*).

Many jurisdictions have implemented mitigations to reduce the frequency of collisions between vehicles and wildlife. Often, this is limited to warning signs installed along highway sections known to have high collision rates (AMEC 2004*). In some other places, highways may have perimeter fencing or even wildlife under- and over-passes to keep animals off the roads, particularly in national parks and wilderness areas (Clevenger 1997; AMEC 2004*; NBDOT 2008*). Such mitigations help prevent animals from entering the right-of-way and are successful in reducing mortality, particularly of mammals (Foster and Humphrey 1995). Interestingly, the effectiveness of animal-crossing signs in reducing collision rates has not yet been quantified (MEDOT 2001*).

Despite the fact that collisions with vehicles are an important source of mortality of wildlife, there has been little research into the phenomenon. Putman (1997) argued that such work is necessary, because understanding the biological and ecological influences 
on road-kill rates is integral to the design and implementation of effective mitigations to deal with this problem. Within this context, the great majority of research into road-kill has dealt with larger mammals. This focus is due to several socio-economic factors, including the danger to people associated with collisions with large mammals, their economic importance in hunting, and their high public profile (Cain et al. 2003; Clevenger et al. 2003). A few studies have also examined factors influencing road-kills of smaller mammals (Garland and Bradley 1984; Clevenger et al. 2003; Saeki and Macdonald 2004).

In the present study the road-kill mortality of largerand medium-sized mammals is examined for a variety of roads in Nova Scotia. Two data sets were used: (a) province-wide incident data for larger mammals over a five-year period, and (b) data for medium-sized mammals over a 20 -month period along a $160-\mathrm{km}$ work-day commute. We examine biological and environmental factors possibly influencing the road-kill rates, including gender, age, and proximity to distinctive habitats.

\section{Methods}

This study was done in Nova Scotia, an eastern province with a population of about 934 thousand people and 23 thousand $\mathrm{km}$ of public roads (NSDTPW 2008*). Data for larger mammals were obtained from incident reports of the Nova Scotia Department of Natural Resources (NSDNR), which records road-kill of White-tailed Deer, Moose (Alces alces), and Black Bear (Ursus americanus), including the location, date, species, sex, and age of the dead animals. Although the reporting of kills is not mandatory, NSDNR estimates that $60-90 \%$ of bear and deer collisions and all involving Moose are reported to them (see Conover et al. 1997). The original NSDNR data were taken from a FoxPro database and converted to Excel spreadsheets. The original location coordinates were converted to UTM using ArcView software to allow for analysis by a geographical information system (GIS).

The number of road-kills for each species was summed monthly and annually from 1999 through 2003. The data for White-tailed Deer and Moose were also analyzed by gender and by yearling and multiyear animals. A GIS analysis was used to plot the distribution of road-kills on digital maps, and spatial relationships with road type and traffic volume were examined. In cases where the carcass was not found immediately beside a road, because the wounded animal had moved before it died, the nearest road was inferred as the place of impact. The traffic volume of highway segments was identified for reaches between successive exits and interchanges, using archived data from NSDTPW (2008*). The 100-series highways of Nova Scotia have relatively high traffic volumes and are often four lanes with controlled access, while the trunk highways are relatively low-volume, two-laned, and have free access. The annual road-kill data were standardized on a per-km and per- $10^{4}$ vehicles basis, and were compared across highway types and on the basis of adjacent habitat (categories were: mature softwood forest ( $>60 \%$ conifer trees), mature hardwood ( $>60 \%$ angiosperm trees), mature mixedwood, immature forest, agricultural, and urban land-use; a separate analysis involved surface water within $100 \mathrm{~m}$.

The relationship of road-kill density was also compared with indicators of local species abundance for White-tailed Deer and Moose. For deer, density was indicated by county-level Pellet Group Inventory (PGI) data (obtained by NSDNR in the spring, after snowmelt but before green-up, along 460 random $1 \mathrm{~km} \times 2 \mathrm{~m}$ transects throughout the province). For Moose, the abundance polygons of Snaith (2001) were used.

Data for smaller mammals were collected over a 20-month period during 1993 through 1994 along a $160-\mathrm{km}$ weekday commuting route (by M. Crowell) from the rural village of Urbania to the urban Burnside Industrial Park in Dartmouth. The route included $106 \mathrm{~km}$ of 100-series highway (part of Highway 102), $38 \mathrm{~km}$ of trunk highway (Highway 215), and $16 \mathrm{~km}$ of urban road. Animals observed dead beside the road were identified to species, as juvenile or adult, and the location was mapped. The annual road-kill data were standardized per $\mathrm{km}$ of road, per $\mathrm{km}^{2}$ of road-bed, and per $10^{4}$ vehicles of traffic density (using archived data from NSDTPW (2008*)). The total-kill data and that for Raccoon (Procyon lotor), Porcupine (Erethizon dorsatum), and Striped Skunk (Mephitis mephitis) were analyzed with respect to adjacent habitat along the surveyed reaches of 100-series highway, including: (a) roadbed being lower than, raised, or level with the adjacent terrain; (b) adjacent habitat being mature softwood forest, mature hardwood, mature mixedwood, immature forest, agricultural, or urban land-use; and (c) surface water within $100 \mathrm{~m}$. A coefficient of similarity was used to make pair-wise comparisons of the relative dominance of species among road-types: $\mathrm{S}_{\mathrm{s}}=2 \mathrm{C} /(\mathrm{A}+\mathrm{B})$, where $\mathrm{C}$ is the number of species killed on both road-types, while $A$ and $B$ are the numbers on particular road-types.

\section{Observations and Discussion} White-tailed Deer

A total of 10397 White-tailed Deer were reported killed in vehicle collisions from 1999 through 2003, or an annual average of 2079 . This mortality is equivalent to about $6 \%$ of the estimated deer population, and is a $28 \%$ increment on top of the reported hunt (on average, hunters take $20 \%$ of the Nova Scotia herd during the fall hunt; NSDNR 2007*). The road-kill rate was similar during 1999 through 2001 (average \pm SD: $2137 \pm 102$ ), but greater than during 2002 and 2003 (1 $449 \pm 44 ; P=0.003$ for difference between the groups of years). The smaller road-kill of 20022003 is likely related to a reduced deer herd during that period (NSDNR 2007*).

There was a bimodal pattern of peak mortality of multi-year individuals (of both sexes) during June- 
July and October-November (Figure 1a). Other authors have reported a fall peak of deer road-kill, and have attributed this to breeding activities (Puglisi et al. 1974; Case 1978). During the rut, bucks move about in search of receptive females, and does are also relatively vagile during that period (Banfield 1974). The fall hunting season may also increase road-kill rates (Puglisi et al. 1974; Allen and McCullough 1976), although Kilgo et al. (1998) found that deer in Florida generally avoid roads and other open areas when under hunting pressure. The increase of deer road-kill in June-July could be related to such factors as increased rural traffic associated with tourists and cottagers, the availability of high-quality forage and residual de-icing salt along verges, harassment by biting flies and partial refuge from them in open areas, and increased mobility of does with fawns during this time. Puglisi et al. (1974) commented on the attractiveness of early-greening road verges to deer in the springtime. We observed a particularly large peak of road-kill in the spring of 2001 following an extremely harsh winter, during which about half of the provincial herd starved to death because of deep snow cover (NSDNR 2007*).

Adult females were 1.8-times more likely to be killed in vehicle collisions than adult males. This is likely due to the Nova Scotian deer herd being disproportionately female because of the selective removal of males by hunters (Feldhamer et al. 1986; Bruinderink and Hazebroek 1996). Yearling mortality was $11 \%$ of the total road-kill mortality, and the kill rate was similar to that of adults (when standardized by estimated population size), although there was little seasonality of the yearling mortality.

The road-kill rate was higher on two-lane secondary highways $(0.38 \mathrm{kills} / \mathrm{km} . \mathrm{yr})$ than on four-lane 100 -series highways $(0.13 / \mathrm{km} . \mathrm{yr})$. Bashore et al. (1985) made a similar observation in Pennsylvania, where there were more deer road-kills along two-lane roads than along a larger interstate highway. Putman (1997) found that deer would routinely cross secondary roads within their territory, but would avoid larger interstate highways, likely because of their greater width and faster and more plentiful traffic.

The road-kill rate per $10^{4}$ vehicles was higher on secondary $\left(0.092 / 10^{4}\right.$ vehicles $)$ than on 100 -series highways $\left(0.012 / 10^{4}\right)$. Overall, however, we did not find a clear relationship between road-kill rates and traffic volume at most of the tested spatial scales, suggesting that more cars do not directly relate to more accidents. Carbaugh et al. (1975) also did not find a linear relationship between traffic density and deer kills, and Armstrong $\left(2005^{*}\right)$ reported a slight inverse relationship. Although we did not examine the phenomenon, it is likely that high traffic rates during crepuscular hours would be particularly lethal to deer trying to cross roads (Allen and McCullough 1976).

We observed seven clusters of deer road-kills, each located near a human population centre with a highdensity road network. A linear regression using average county data found a positive correlation between the estimated density of deer and that of road-kill $\left(\mathrm{R}^{2}=0.71\right.$; $P<0.01)$.

In some areas, road-kill may exert a controlling influence on local deer populations and slow their recovery from high winter mortality. There are economic implications of such effects because White-tailed Deer are the most valuable wildlife resource in North America in terms of hunting (Conover 1997; DuWors et al. 1999*). Romin and Bissonette (1996) estimated that the inclusive value of deer in North America is about $\$ 2200$ per animal (Canadian dollars adjusted for inflation to 2005).

\section{Moose}

Seventy Moose were reported killed in vehicle collisions from 1999 through 2003 (average = 14/yr). About two-thirds of the mortality involved the relatively abundant population on the highlands of Cape Breton, which is derived from 18 released individuals (Alces alces andersoni) imported from Alberta in the late 1940s (Pulsifier and Nette 1997). The annual road-kill mortality is equivalent to about $0.23 \%$ of the Cape Breton population, and $3.7 \%$ of the reported harvest by hunters (in 2003; this does not include the Mi'kmaq harvest, which is estimated to be similar to or exceeding the licenced hunter harvest). However, the native mainland population of Moose (Alces alces americana) is much less abundant, likely fewer than a thousand individuals, and since 2003 it has been listed as endangered under the Nova Scotia Endangered Species Act. The annual road-kill mortality of mainland Moose is equivalent to about $0.5 \%$ of the population (there is no legal hunting of this population).

Moose road-kills occurred in all months except April, with a peak of male mortality in October, and of females during June-July (Figure 1b). The autumn peak of male mortality occurs during the rut, when they are competing and moving about in search of receptive females (Banfield 1974). Males also become more aggressive during the rut and may be less averse to roads and traffic (Joyce and Mahoney 2001). The female peak of road-kill in early summer is related to the high volume of tourism-related traffic that occurs then on Cape Breton highways, particularly on the Cabot Trail.

Similar numbers of males and females were killed on the mainland (10 vs. 12 ), but 1.6-times more females were killed on Cape Breton roads. The latter observation is related to the female-skewed sex distribution of Moose on Cape Breton (the gender ratio of kills by hunters is about three males per two females). Yearling mortality was $11 \%$ of the total, but their kill rate was similar to that of adults (when standardized by their estimated population size). There was no obvious seasonality of the yearling mortality.

Of the road-kills on Cape Breton, $85 \%$ occurred along eastern sections of the Cabot Trail, where traffic volumes are relatively high. The highest kill rate $(0.4 / 10 \mathrm{~km}$. yr) occurred along a stretch from French 
River Bridge to Wreck Cove along the Cabot Trail, within Cape Breton Highlands National Park. On mainland Nova Scotia, the highest road-kill rate was on Highway 104 on the upland Cobequid Pass Toll highway, where $38 \%$ of the mainland kills occurred $(0.2 / 10 \mathrm{~km} . \mathrm{yr})$. These high-kill areas coincide with regions of Nova Scotia that have the highest density of Moose (Snaith 2001).

\section{Black Bear}

One hundred and sixty-four Black Bears were reported killed in vehicle collisions from 1999 through 2003 (average $=33 / \mathrm{yr}$ ). The annual mortality is equivalent to about $0.5 \%$ of the estimated population of Black Bears in Nova Scotia, and $7.2 \%$ of the reported harvest by hunters (in 2003). The lowest kill-rate was in 1999 (10 individuals) and the highest in 2003 (57). An unusually large number of 27 bears were road-killed in June 2003, compared to the 1999-2002 June average of 5. This may have been due to an increasing bear population, or the springtime of 2003 being unusually cool and wet, so that animals emerging from hibernation had trouble finding adequate natural food and were attracted to areas near human settlement.

There was a bimodal pattern of road-kill mortality, with peaks in May-June and in October-November (Figure 1c). The first peak is likely due to activity associated with the breeding season, when males wander in search of females (Klenney 1987). The early summer is also when sub-adult animals, at about 15 months of age, leave their mothers to find their own territory (Matson 1967). The fall peak of mortality is likely related to activity associated with pre-hibernation feeding and movement to denning sites (Matson 1967; Davis and Browne 1996). No road-kills were recorded from mid-November to early April, when bears are in hibernation. It was not possible to factor the influence of age or sex on bear road-kill, as these data were not consistently recorded.

Bear road-kills occurred throughout the province, except in southeastern Cape Breton, where the species does not have an established population (Macmichael 2007). The 100-series highways had a higher linear mortality rate $(1.58 \mathrm{kills} / 100 \mathrm{~km} . \mathrm{yr})$ than secondary highways $(0.032 / 100 \mathrm{~km} . \mathrm{yr})$. According to traffic density, however, the 100-series and secondary highways had similar mortality rates (both 0.02 kills $/ 10^{6}$ vehicles.year). Relative to their total estimated population size in Nova Scotia, Black Bear road-kill rates are lower than those of White-tailed Deer. This may be due to bears being relatively wary of humans and roads, except for habituated animals (Herrero 1985). In addition, deer tend to be relatively abundant in areas of Nova Scotia with high populations of people, especially in agricultural and coastal regions.

\section{Other Mammals}

Three hundred and ninety-two smaller mammals of sixteen species were recorded as road-kill on a $160-\mathrm{km}$ study route during a 20-month survey (Figure 1d). The most frequent mortalities were of Raccoon (28\% of kills), Porcupine (27\%), and Striped Skunk (18\%). These are relatively abundant in the study area, often occurring near roads and other habitat edges, and are at inherent risk because they are relatively deliberate in their movements and have a body too large to pass beneath most moving vehicles without impact (Garland and Bradley 1984; Rolley and Lehmen 1992; Clevenger et al. 2003). All species recorded as road-kill are indigenous to the study area, except for Coyote, Canis latrans, domestic cat, Felis domesticus, and domestic dog, Canis familarus (Banfield 1974; Davis and Browne 1996). Additionally, a Red-necked Wallaby (Macropus rufogriseus) that had been a 6-month escapee from a wildlife park was found by one of us as road-kill in the Annapolis Valley of Nova Scotia.

Discoveries of small-mammal road-kills (rodents and shrews) were uncommon, but this is likely due to the difficulty of detecting these animals when scanning from a moving vehicle, plus the likelihood that they are quickly scavenged. In addition, small mammals are reluctant to cross multi-lane highways (Clevenger et al. 2003). An innate reluctance to cross open spaces may also explain why Snowshoe Hare, Lepus americanus (the most abundant medium-sized mammal in the study area), was killed less frequently than Raccoon, Porcupine, or Striped Skunk, and why their kill rate was higher on the two-lane Highway 215 than on the four-lane Highway 102. Clevenger et al. (2003) also found that Snowshoe Hare was more likely to be killed on narrow roads than on wider ones in Banff National Park, Alberta.

The road-kill rate, when standardized by distance surveyed, was highest on the four-lane Highway 102 $(6.0 \mathrm{kills} / \mathrm{km})$ than on the two-lane Highway 215 $(4.0 / \mathrm{km})$ or city streets $(1.3 / \mathrm{km})$. However, when standardized to traffic density, Highway 215 had a greater rate of mortality (6.3 kills $/ 10^{4}$ vehicles) than Highway $102\left(1.9 / 10^{4}\right.$ vehicles). The kill rate per $10^{4}$ vehicles approached zero on urban streets because of the large traffic volumes, lower vehicle speeds, and likely a relatively small abundance of wild mammals. The lower rate on Highway 102 is likely due to its much greater width and larger volume of faster-moving vehicles, which likely discouraged animals from crossing. Clevenger et al. (2003) also found that relatively wide and high-traffic roads discouraged small- and medium-sized mammals from crossing in Alberta, as did Clarke et al. (1998) for badgers in England.

Similar numbers of species were observed killed on the four-lane Highway $102(n=12)$ and on the secondary Highway $215(n=11)$, and both exceeded urban streets (only Red Squirrel, Tamiasciurus hudsonicus, were observed road-killed in the urban area studied). The most frequent mortalities on the secondary Highway 215 were Raccoon (19\% of the total), Striped Skunk (18\%), Red Squirrel (16\%), Snowshoe Hare 
(a) White-tailed Deer

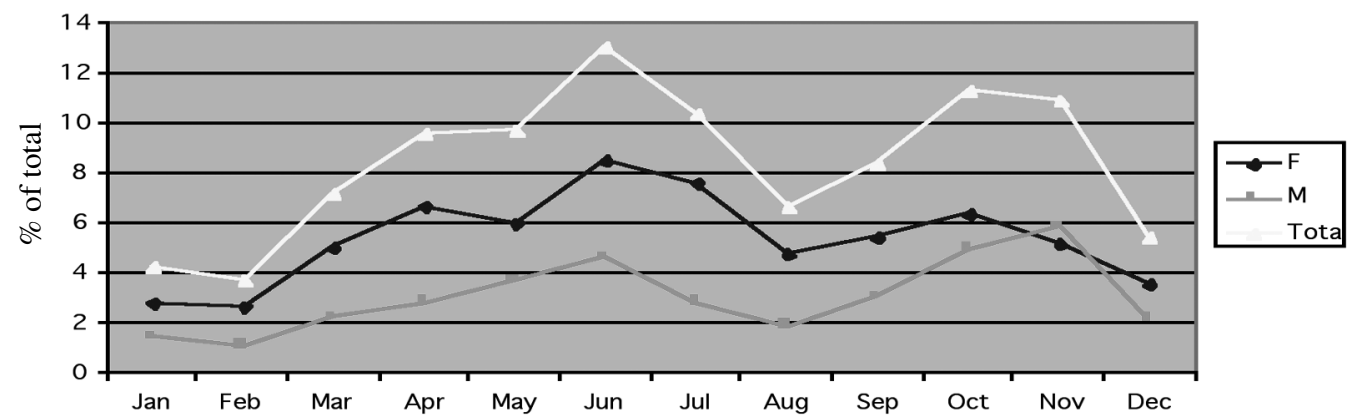

(b) Moose

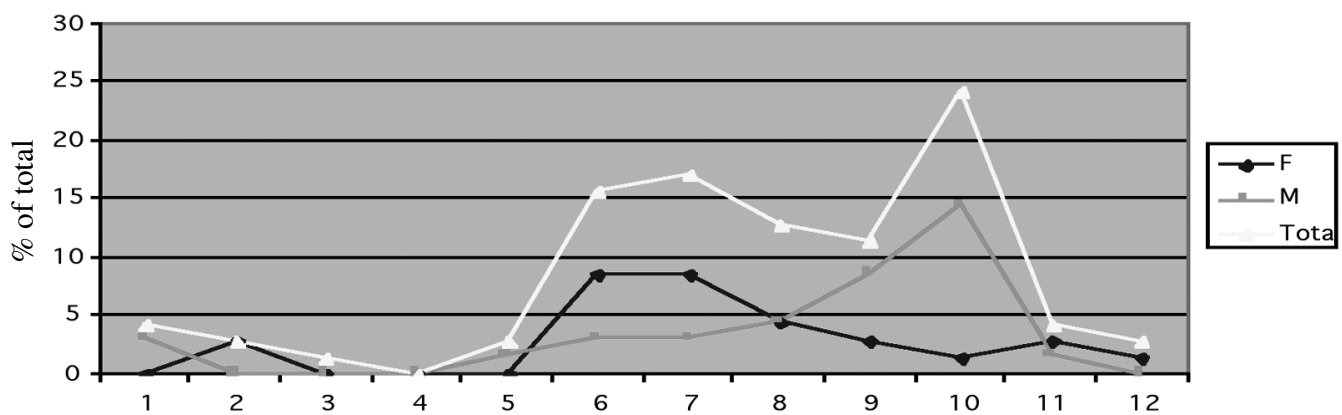

(c) Black Bear

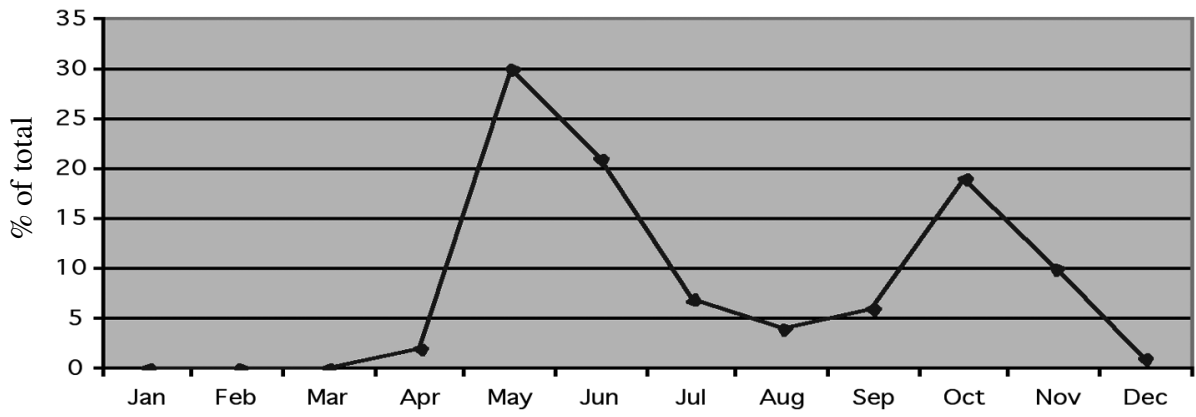

(d) Smaller Mammals

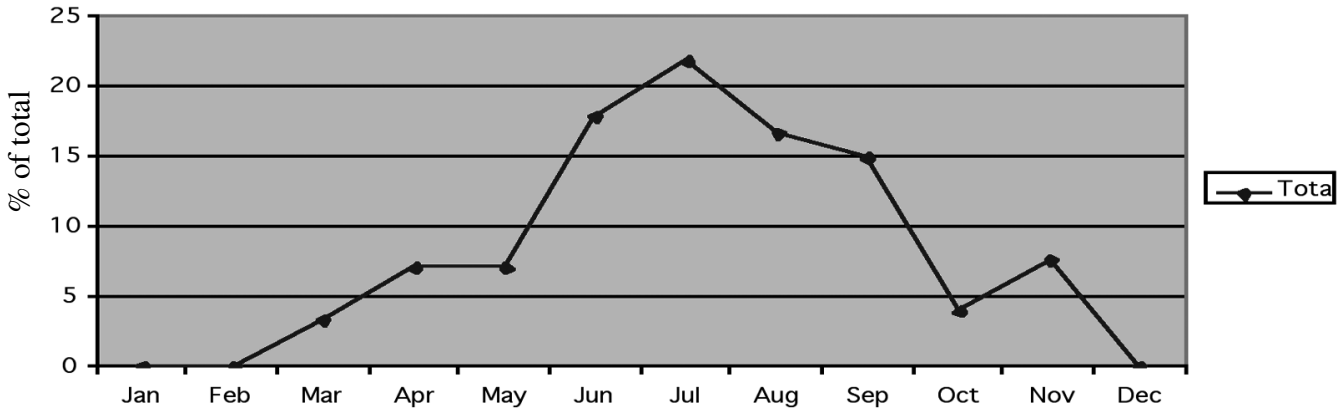

FIGURE 1. Average monthly road-kill mortality of large mammals from 1999 through 2003: (a) White-tailed Deer $(n=10$ 397); (b) Moose $(n=70)$; (c) Black Bear $(n=164)$; (d) smaller mammals $(n=392)$. Sum of genders may not add to totals, because the sex of some animals was not identified. 
(14\%), and Porcupine (11\%). The most frequent on the four-lane Highway 102 were Porcupine (31\%), Raccoon (30\%), and Striped Skunk (18\%). The species spectrum of mortality of Highways 102 and 215 had a similarity coefficient of 0.78 , but their similarity with urban streets was very low - only 0.00 and 0.08 , respectively.

The greatest rate of road-kill occurred in the summer months of June (35 mortalities), July (34) and August (22) (Figure 1d). Smaller numbers were recorded in the winter months of November through February, when animals are hibernating or generally less active. The road-kill of Raccoons was highest in May and June, when adult males search widely for females with which to mate (Banfield 1974). In addition, $43 \%$ of the Raccoon mortality in May and June was yearlings, which disperse during that time. The mortality of Striped Skunks was highest in September, when juveniles disperse from their natal home range. The mortality of Porcupines was relatively even throughout the spring, summer, and fall.

Partial-deviance tests indicate that roadside topography and habitat were significant predictors of Raccoon road-kill. The likelihood of a Raccoon road-kill was much greater at level roadside topography $\left(\chi^{2}=11.3\right.$, df $=3, P<0.001)$ and along segments of highway bisecting mature forest $\left(\chi^{2}=9.4\right.$, df $\left.=3, P<0.05\right)$. Proximity to water did not have a significant effect $\left(\chi^{2}=0.50\right.$, df $\left.=1, P>0.05\right)$. The likelihood of Raccoon road-kill at different roadside topographies was assessed using log-likelihood ratios, and was much greater at level crossings $(\mathrm{T}$-value $=3.1 ; P<0.05)$ and along segments bordering mature forest $(\mathrm{T}$-value $=5.9$; $P<0.0025)$. For Porcupines, topography $\left(\chi^{2}=29.4\right.$, $\mathrm{df}=4, P<0.005)$ and proximity to water $\left(\chi^{2}=5.9\right.$, $\mathrm{df}=1, P<0.025)$ were significant predictors of roadkill. Log-likelihood ratios indicate that road-kill was most frequent at level roadside topography (T-value $4.1 ; P<0.025)$ and adjacent to mature softwood forest (T-value 4.0; $P<0.025)$. For Striped Skunks, topography $\left(\chi^{2}=27.4\right.$, df $\left.=2, P<0.005\right)$ was the only significant predictor of road-kill, and the log-likelihood of mortality was much higher at level roadside topography $($ T-value $=4.1 ; P<0.025)$.

Overall, no road-kills of any species were observed at sites where the roadbed was raised (higher than the adjacent terrain), and the likelihood of road-kill was higher on roads bisecting mature forest (mixed, softwood, or hardwood) than adjacent to immature forest, agricultural fields, or urban habitat (T-value 3.8; $P<0.05)$. Proximity to water did not have an overall significant predictive effect.

The results suggest that far fewer road-kills occurred on raised than on level or buried roadbeds. Raised roadbeds could serve as a visual barrier to habitat on the other side, and the banked incline may act as a physical deterrent to crossing. Clevenger et al. (2003) made similar observations for smaller-animal road- kills in Banff National Park, where raised roadbeds had a lower risk of mortality than other topographies.

Another factor potentially affecting road-kill rates is the presence of vegetated center medians on divided highways, such as the grassy ones occurring on Highway 102 in the present study. Bellis and Graves (1971) suggest that these habitats function as temporary refuge areas for animals attempting to cross major highways.

Our study does not allow for an assessment of the impact of road-kill mortality on the local abundances of smaller mammals, as population estimates are not available. If our data were extrapolated to the total length of 100 -series $\left(3 \times 10^{3} \mathrm{~km}\right)$ and secondary $\left(4 \times 10^{3} \mathrm{~km}\right)$ highways in Nova Scotia, the estimated annual mortality within this size range would be $20 \times 10^{3}$ mammals. It can be concluded that the numbers of animals killed on Nova Scotian highways is large, and that this is a significant anthropogenic stressor. Our field data for smaller mammals were collected in 1993-1994, and since then traffic volumes on Nova Scotian roads have increased by about $24 \%$ since then (NSDTPW 2008*), so it is likely that road-kill rates have also increased. Moreover, some new roads are being built and the 100-series highways are being expanded, which may also be increasing the rates of road-kill.

\section{Mitigation}

Clearly, large numbers of mammals are being killed on Nova Scotian roads, and the further creation and upgrading of highways and increasing traffic may worsen this situation. Moreover, there are important socioeconomic consequences of collisions with wildlife. These include injuries to people involved in the collisions, the associated medical costs and time off work, damages to property, and decreases in the populations of animals available to be hunted or trapped. For example, during our study period of 1999 through 2003, White-tailed Deer were involved in 204 vehicle collisions in which people suffered injuries requiring hospitalization, and seven incidents involved a human fatality (NSDTPW 2006*). In fact, White-tailed Deer cause more collision-related property damage and human mortality than any other wild animal in North America (Conover 1997). According to Putman (1996), an average collision with a deer costs about \$3 400 in vehicle damage (Canadian dollars, adjusted for inflation to 2005). Using this cost estimate, deer collisions in Nova Scotia during our study period resulted in about $\$ 6.8$ million in annual property damage, not including costs associated with health care and emergency services.

Fortunately, there are ways to reduce road-kill along highways (Woods 1990*; Clevenger et al. 2001; USDOT 2002*; AMEC 2004*). Some mitigations are intended to change the behavior of animals in ways that make them less likely to enter the right-of-way. For example, fencing is used to prevent animals from 
TABLE 1 . Road-kill of smaller mammals over a 20 -month study period.

\begin{tabular}{|c|c|c|c|c|c|c|c|}
\hline \multirow[b]{2}{*}{ Species } & \multicolumn{2}{|c|}{ Highway 101} & \multicolumn{2}{|c|}{ Highway 215} & \multirow{2}{*}{$\begin{array}{c}\text { Urban } \\
n\end{array}$} & \multicolumn{2}{|c|}{ Total } \\
\hline & $n$ & $\%$ & $n$ & $\%$ & & $n$ & $\%$ \\
\hline Raccoon (Procyon lotor) & 97 & 29.9 & 11 & 19.3 & 0 & 108 & 27.5 \\
\hline Porcupine (Erethizon dorsatum) & 101 & 31.2 & 6 & 10.5 & 0 & 107 & 27.3 \\
\hline Striped Skunk (Mephitis mephitis) & 60 & 18.5 & 10 & 17.5 & 0 & 70 & 17.9 \\
\hline Snowshoe Hare (Lepus americanus) & 14 & 4.3 & 8 & 14.0 & 0 & 22 & 5.5 \\
\hline Domestic Cat (Felis domesticus) & 17 & 5.2 & 4 & 7.0 & 0 & 21 & 5.4 \\
\hline Coyote (Canis latrans) & 13 & 4.0 & 0 & 0.0 & 0 & 13 & 3.3 \\
\hline Groundhog (Marmota monax) & 10 & 3.1 & 2 & 3.5 & 0 & 12 & 3.1 \\
\hline Red Squirrel (Tamiasciurus hudsonicus) & 0 & 0.0 & 9 & 15.8 & 3 & 9 & 2.3 \\
\hline Domestic Dog (Canis familiaris) & 4 & 1.2 & 2 & 3.5 & 0 & 6 & 1.5 \\
\hline Red Fox (Vulpes vulpes) & 4 & 1.2 & 0 & 0.0 & 0 & 4 & 1.0 \\
\hline Eastern Chipmunk (Tamias striatus) & 0 & 0.0 & 3 & 5.3 & 0 & 3 & 0.8 \\
\hline Beaver (Castor canadensis) & 1 & 0.3 & 0 & 0.0 & 0 & 1 & 0.3 \\
\hline Mink (Mustela vison) & 1 & 0.3 & 0 & 0.0 & 0 & 1 & 0.3 \\
\hline Muskrat (Ondatra zibethicus) & 1 & 0.3 & 0 & 0.0 & 0 & 1 & 0.3 \\
\hline Red-backed Vole (Clethrionomys gapperi) & 0 & 0.0 & 1 & 1.8 & 0 & 1 & 0.3 \\
\hline Woodland Jumping Mouse (Zapus hudsonicus) & 0 & 0.0 & 1 & 1.8 & 0 & 1 & 0.3 \\
\hline Unknown mammal & 1 & 0.3 & 0 & 0.0 & 0 & 1 & 0.3 \\
\hline Total Species $=16$ & 324 & & 57 & & 3 & 392 & \\
\hline
\end{tabular}

crossing major roadways in at least eleven U.S. states (MEDOT 2001*), New Brunswick, and in the Canadian Rockies. In Banff National Park, for example, fencing resulted in a $96 \%$ reduction in large-mammal road-kill (Clevenger 1997). It is generally recommended that fencing be at least $2.6 \mathrm{~m}$ in height, including above winter snow levels (USDOT 2002*). However, fencing also has drawbacks, because it can fragment populations and may trap animals within a right-ofway that they may enter via a break or at a fence-end (Phillips 1999*). Phillips (1999*) estimated that fencing along a major highway in New Brunswick typically costs $\$ 40000$ to $\$ 80000$ (Canadian) per kilometer. At present, the only areas in Nova Scotia with wildlife fencing along road verges are on the Cabot Trail on Cape Breton Island to prevent devastating collisions with Moose in segments where there are steep drop-offs along the highway, and an area near Magazine Hill in Dartmouth that had experienced a high number of accidents with deer.

Although extremely expensive, structural crossings can be installed to allow for the movement of animals across a right-of-way. This mitigation can help prevent local and even regional populations of certain animals from becoming fragmented, with potentially deleterious consequences, while also avoiding risks to people and property from collisions. Crossing structures include underpasses, overpasses, and modified watercourse structures (a kind of underpass). However, not all animals will use structural crossings. Reed (1981) observed that Mule Deer (Odocoileus hemionus) were reluctant to use enclosed underpasses, and they did not acclimatize to them over a study period of 10 years. He suggested that deer were far more willing to use open "bridge" style overpasses than underpasses. A review by USDOT $\left(2002^{*}\right)$ also concluded that ungu- lates were most likely to use overpass structures. The installation of a single overpass crossing structure can cost Canadian \$1.4-2.6 million, while underpasses and modified watercourse structures are generally $\$ 92000$ to $\$ 420000$ (MEDOT 2001*).

Another useful mitigation is to make drivers more aware of potential dangers and to reduce vehicular speeds (AMEC 2004*). These driver-orientated approaches include signage and educational programs. Passive warning signs (sometimes with flashing lights) of White-tailed Deer and Moose are used in many places in Nova Scotia and elsewhere to alert motorists to increased risks of collision with wildlife, generally in places where repeated collisions have occurred (AMEC 2004*). Although there are no data supporting the efficacy of signs, they likely have limited effectiveness because they rely on driver attentiveness, yet people quickly become desensitized to them (USDOT, $\left.2002^{*}\right)$. Passive signs are, however, relatively inexpensive to install and maintain.

Driver education related to road-kill may make motorists more aware of the potential for wildlife encounters, and therefore better prepared to avoid them. For example, a program called "Watch out for Wildlife" is delivered in the public-school system and by driver-education messaging in Florida (Evink 1999). The effectiveness of education programs in reducing road-kill is difficult to quantify, although people skilled at spotting animals and predicting their behaviour tend to be involved in fewer collisions (Joyce and Mahoney 2001).

In Nova Scotia, enhanced public awareness of wildlife-collision risks could be promoted by an increased educational program. In addition, fencing verges in stretches of all major roads known to have high kill rates of larger mammals would reduce hazards, partic- 
ularly for conservation of the at-risk mainland Moose population along the Cobequid Pass of Highway 104 (which also has high rates of bear and deer road-kills). However, roadside fencing could also detrimentally fragment the habitat of the already-small populations of mainland Moose in these areas.

Of course, mitigations have significant costs, but they provide large benefits by reducing property damage and risks of injury to people and wildlife.

\section{Acknowledgments}

This work was supported by a Discovery Grant to BF from the Natural Sciences and Engineering Research Council of Canada. Lester Hanley of the Nova Scotia Department of Transportation provided traffic statistics for roads, Jennifer Milne and James Boxall of Dalhousie University assisted with the GIS analysis, and Cathy Wambolt with statistical analysis.

\section{Documents Cited (marked $*$ in text)}

AMEC. 2004. Mainland Moose: Status, Potential Impacts, and Mitigation Considerations of Proposed Highway 113 Unpublished Research Report by AMEC Industrial to Nova Scotia Department of Transportation and Public Works.

Armstrong, K. E. 2005. Deer-Related Automobile Accidents: Using GIS and GPS to Analyze Trends and Find Solutions. GIS Café, GIS Technical Papers. http://www. giscafe.com/technical_papers/Papers/paper005/.

DuWors, E., M. Villeneuve, F. L. Filion, R. Reid, P. Bouchard, D. Legg, P. Boxall, T. Williamson, A. Bath, and S. Meiss. 1999. The Importance of wildlife to Canadians. Canadian Wildlife Service, Ottawa, Ontario. http:// www.ec.gc.ca/nature/highlights/prepare.html

MEDOT (Maine Department of Transportation). 2001. Collisions Between Large Wildlife Species and Motor Vehicles in Maine, Interim Report. Maine Interagency Work Group on Wildlife/Motor Vehicle Collisions, Bangor, Maine. http://mainegov-images.informe.org/mdot/ safety-programs/pdf/moosereport.pdf.

NBDOT (New Brunswick Department of Transport). 2008. Protect Yourself and Your Family from Moose-Vehicle Collisions. NBDOT, Fredericton, New Brunswick. http://www.gnb.ca/0113/moose/alert-e.asp.

NSDNR (Nova Scotia Department of Natural Resources). 2006. The Furbearers and Upland Game Program. NSDNR, Halifax, Nova Scotia. http://www.gov.ns.ca/natr/ wildlife/furbers/furbs.htm

NSDNR (Nova Scotia Department of Natural Resources). 2007. Large Mammals Program project reports, NSDNR, Halifax, Nova Scotia. http://www.gov.ns.ca/natr/wildlife/ lgmams/lgm.htm

NSDNR (Nova Scotia Department of Natural Resources). 2008. Recovery Plan for Moose (Alces alces americanana) in Mainland Nova Scotia. NSDNR, Halifax, Nova Scotia. http://www.gov.ns.ca/natr/wildlife/biodiv/ species_recovery/recoveryplans/MainlandMooseRecover yPlan.pdf

NSDTPW (Nova Scotia Department of Transportation and Public Works). 2006. Motor Vehicle Collision Statistics, NSDTPW, Halifax, Nova Scotia. http://www.gov. ns.ca/tran/publications/CCMTA_2005.pdf
NSDTPW (Nova Scotia Department of Transportation and Public Works). 2008. Traffic Volumes Primary Highway System. NSDTPW, Halifax, Nova Scotia. http://www. gov.ns.ca/tran/

Phillips, M. 1999. Wildlife management on arterial highways in New Brunswick. Third International Conference on Wildlife Ecology and Transportation. September 13-16, 1999. http://www.dot.state.fl.us/emo/sched/wildlife.pdf

USDOT (United States Department of Transportation). 2002. Wildlife Habitat Connectivity Across European Highways, publication FHWA-PL-02-011. http://interna tional.fhwa.dot.gov/Pdfs/wildlife_web.pdf

Woods, J. G. 1990. Effectiveness of Fences and Underpasses on the Trans-Canada Highway and their Impact on Ungulate Populations in Banff National Park. Unpublished Research Report, Banff National Park, Banff, Alberta.

\section{Literature Cited}

Allen, R. E., and D. R. McCullough. 1976. Deer-accidents in southern Michigan. Journal of Wildlife Management 40: 317-325.

Banfield, A. W. F. 1974. The Mammals of Canada. National Museum of Natural Sciences and University of Toronto Press, Toronto, Ontario.

Bashore, T. L., W. M. Tzilkowski, and E. D. Bellis. 1985. Analysis of deer-vehicle collision sites in Pennsylvania. Journal of Wildlife Management 49: 769-774.

Bellis, E. D., and H. B. Graves. 1971. Deer mortality on a Pennsylvania interstate highway. Journal of Wildlife Management 35: 769-774.

Bennet, A. F. 1991. Roads, roadsides and wildlife conservation: A review. Pages 156-165 in Nature Conservation: the Role of Corridors. Edited by D. A. Saunders and R. J. Hobbs. R. J. Surrey Beatty, Chipping Norton, Australia.

Bensen, D. A. 1977. The Deer of Nova Scotia. Department of Lands and Forests, Halifax, Nova Scotia.

Bruinderink, G. W. T. A., and E. Hazebroek. 1996. Ungulate traffic collisions in Europe. Conservation Biology 10: 1059-1067.

Cain, A. T., V. R. Tuovila, D. G. Hewitt, and M. E. Tewes. 2003. Effects of a highway and mitigation projects on bobcats in Southern Texas. Biological Conservation 114: 189-197.

Carbaugh, B., J. P. Vaughan, E. D. Bellis, and H. B. Graves. 1975. Distribution and activity of White-tailed Deer along an interstate highway. Journal of Wildlife Management 39: 570-581.

Case, R. M. 1978. Interstate highway road-killed animals: A data source for biologists. Wildlife Society Bulletin 6: 8-13.

Clarke, G. P., P. C. L. White, and S. Harris. 1998. Effects of roads on Badger Meles meles populations in south-west England. Biological Conservation 86: 117-124.

Clevenger, A. 1997. Highway effects on wildlife in Banff National Park. Research Links 5: 1-2. Parks Canada, Ottawa, Ontario.

Clevenger, A. P., B. Chruszcz, and K. Gunson. 2001. Highway mitigation fencing reduces wildlife-vehicle collisions. Wildlife Society Bulletin 29: 646-653.

Clevenger, A. P., B. Chruszcz, and K. E. Gunson. 2003. Spatial factors influencing small vertebrate fauna roadkill aggregations. Biological Conservation 109: 14-26. 
Conover, M. R. 1997. Monetary and intangible valuation of deer in the United States. Wildlife Society Bulletin 25: 298-305.

Davis, D. S., and S. Browne. 1996. The Natural History of Nova Scotia. I. Topics and Habitats. Nova Scotia Museum and Nimbus Publishing, Halifax, Nova Scotia.

Evink, G. L. 1999. Watch Out for Wildlife. Page $301 \mathrm{in}$ : Third International Conference on Wildlife Ecology and Transportation, Proceedings, FL-ER-73-99. Florida Department of Transportation, Tallahassee, Florida.

Feldhamer, G. A., J. E. Gates, D. M. Harman, A. J. Loranger, and K. R. Dixon. 1986. Effects of interstate highway fencing on White-tailed Deer activity. Journal of Wildlife Management 50: 497-503.

Foster, M. L., and S. R. Humphrey. 1995. Use of highway underpasses by Florida Panthers and other wildlife. Wildlife Society Bulletin 23: 207-231.

Garland, T., and W. G. Bradley. 1984. Effects of a highway on Mojave Desert rodent populations. American Midland Naturalist 111: 47-56.

Harris, L. D., and P. B. Gallagher. 1989. New initiatives for wildlife conservation: The need for movement corridors. Pages 11-34 in Preserving Communities and Corridors. Edited by G. Mackintosh. Defenders of Wildlife. Washington, DC.

Herrero, S. M. 1985. Bear Attacks - Their Causes and Avoidance. Winchester Press, New Century Publishing Inc., Piscataway, New Jersey.

Joyce, T. L., and S. P. Mahoney. 2001. Spatial and temporal distributions of moose-vehicle collisions in Newfoundland. Wildlife Society Bulletin 29: 281-291.

Kilgo, J. C, R. F. Labisky, and D. E. Fritzen. 1998. Influences of hunting on the behavior of White-tailed Deer: Implications for conservation of the Florida Panther. Conservation Biology 12: 1523-1539.

Klenney, W. 1987. Seasonal movements and home range utilization patterns of the Black Bear, Ursus americanus, in western Manitoba. Canadian Field-Naturalist 101: 558568.

Macmichael, C. 2007. Use of Provincial Black Bear (Ursus aericanus) Habitat Associations to Assess the Lack of an Established Population in Southeastern Cape Breton, Nova Scotia, Canada. Master of Environmental Studies thesis, Dalhousie University, Halifax, Nova Scotia.
Matson, J. R. 1967. The Adaptable Black Bear. Dorrance and Co., Philadelpha, Pennsylvania.

Puglisi, M. J., J. S. Lindzey, and E. D. Bellis. 1974. Factors associated with highway mortality of White-tailed Deer. Journal of Wildlife Management 38: 799-807.

Pulsifier, M. D., and T. L. Nette. 1997. History and present distribution of Moose in Nova Scotia. Alces, 31: 209219.

Putman, R. J. 1997. Deer and road traffic accidents: Options for management. Journal of Environmental Management 51: 43-57.

Reed, D. F. 1981. Mule Deer behavior at a highway underpass exit. Journal of Wildlife Management 45(2): 542543.

Rolley, R. E., and L. E. Lehmen. 1992. Relationship among Raccoon road-kill surveys, harvests and traffic. Wildlife Society Bulletin 20: 313-318.

Romin, L. A., and J. A. Bissonette. 1996. Deer-vehicle collisions: Status of state monitoring activities and mitigation efforts. Wildlife Society Bulletin 24: 276-283.

Saeki, M., and D. W. MacDonald. 2004. The effects of traffic on the Raccoon Dog (Nyctereutes procyonoides viverrinus) and other mammals in Japan. Biological Conservation 118: 559-571.

Snaith, T. V. 2001. The Status of Moose in Mainland Nova Scotia: Population Viability and Habitat Suitability. Master of Resource and Environmental Studies thesis (MRES), Dalhousie University, Halifax, Nova Scotia.

Tewes, M. E., and D. R. Blanton. 1998. Potential impacts of international bridges on Ocelots and Jaguarundis along the Rio Grande wildlife corridor. Pages 135-139 in Proceedings of the International Conference on Wildlife Ecology and Transportation. Edited by G. L. Evink, P. Garrett, D. Zeigler, and J. Berry. FL-ER-69-98, Florida Department of Transportation, Tallahassee, Florida.

Tewes, M. E., and R. W. Hughes. 2001. Ocelot management and conservation along transportation corridors in southern Texas. Pages 559-564 in Proceedings of the International Conference on Ecology and Transportation, Keystone, Colorado.

Received 13 September 2006

Accepted 15 April 2008 